\title{
Experimental Analysis on Freezing Adhesive Yield Characteristics of Solid Snow-ice
}

\author{
Li Yaqin ${ }^{1,2}$, WuWenfu ${ }^{1}$, Wang Junfa ${ }^{2 *}$, Li Xiaoxia ${ }^{2}$ and Wang Rui ${ }^{2}$ \\ ${ }^{1}$ Biological and Agricultural Engineering College, Jilin University, Changchun \\ 130022, China \\ ${ }^{2}$ College of Mechanical Engineering, Jiamusi University, Jiamusi 154007, China \\ wangjunf2934@sina.com
}

\begin{abstract}
At winter the problem that how to efficiently clear solid ice and snow, which alwys plagues the staff.The interfacial materials-solid snow-ice-cause the major operational problem related to snow removed performance. The central issue is how to evaluate the yield characteristics when the solid snow-ice was broken and fracture failure Measurement system of freezing adhesive yield characteristics was established and solid snow-ice freezing adhesive yield characteristics were tested. From the experiment process that simulating snow-ice repeatedly compacted by vehicles on practical road the total strain $\varepsilon$ of solid snowice under the effect of cyclic load is the sum of pure elastic strain $\varepsilon_{e}$, delayed elastic strain $\varepsilon d$ and permanent strain $\varepsilon_{v}$. The total strain cwas measured by the DH3818 strain gages, according to the strain curve, the strein showed as luchated change along with the load applied, the strain value changed as a process of increase-decrease-increase. The rotating orthogonal test was conducted by using the average of single group strain as objective function, thickness of snow layer, now-ice density and snow-ice firmness are as influencing factors. Through the test result, the major and minor relation of three factors are thickness of snow layer>snow-ice density snow-ice firmness, and the thickness of snow layer has the interaction with density and firmness. From the analysis, the optimal average strain is 0.128 to 0.14 which can be got by the eltow parameter combination: the range of snow density is $500 \mathrm{~kg} / \mathrm{m}^{3}-518 \mathrm{~kg} / \mathrm{m}^{3}$ the range of thickness of snow layer is $6.9 \mathrm{~mm}-7.5 \mathrm{~mm}$, the range of snow firmness is 1826Pa-2040Ra. Through the study, the constitutive model of solid snow-ice can be established, meanwhile, the certain theoretical basis for efficient solid snow-ice clearing has been provided.
\end{abstract}

Keywords: solid snow-ice, freezing adhesive, yield characteristics, experimental analysis

\section{Introduction}

Snow-ice is formed by the winter snowfall that repeatedly compacted by vehicles and pedestrians, repeatedly thawed and froze by the changing of temperature. Snow-ice is hard, icing surface, containing impurities and bond firmly with road surface. All that snow-ice is called solid snow-ice. The freezing adhesion between snow-ice and road surface caused great influence to the safe operation of traffic vehicles and work efficiency [1]. In addition to considering the freezing adhesive characteristics between snow-ice crystals, more considerations should be given freezing adhesive characteristics of bond coat between solid snow-ice with road surface. The practical effect of mechanical snow clearing largely depends on the freezing adhesion of bond coat, the external effect mainly shown as bond force and also known as adhesion or grip force. 
According to the experiment and analysis of force [2], the resistance of clearing-snow tools mainly comes from the freezing adhesion between solid snow-ice with road surface. Research showed that the characteristics of freezing adhesive bond coat are the key factor affecting the rate of snow-ice clearance and the rate of remove.

Now, the freezing adhesive experiment for freezing adhesive characteristics is mostly about the research of anti-icing system of aircraft and clearing ice technology, aiming at minimizing icing or making icing off quickly. The corresponding theories are mainly about three aspects [3], the freezing adhesive surface layer, the main factor influencing of the freezing adhesion and the material properties. The formation mechanism of freezing adhesion attaching on solid surface was given by L.Ritz [4]. The physical adhesive process in snow-ice was proposed by IvanA.Ryzhkin [5]. The better the match between solid surface with ice lattice the better the adhesive force was revealed by Nishikant [6]. All the above theoretical analysis are a single level of freezing adhesive theoretical analysis that supposing the second interface is metal, which still can't explain all of the freezing adhesive phenomenon, especially the analysis for freezing adhesive yield characteristics of solid snow-ice bond coat are rarely reported.

Most scholars researching the mechanical characteristics of snow-ice sill argued that snow-ice is 'low-temperature material' [7-12]. In fact there is heat produced by the interaction between tires with solid snow-ice and pressure melting phenomenon [13] in the process of actual snow-ice repeatedly compacted, moreover, the winter road surface polluted by the impurities and the exhaust. These impurities greatly affect the crystalline state and freezing adhesive characteristics of the snow-ice mixture. The morphology between the crystals might be damaged by the impurity particles especially in the process of compacted thus leading to the changes of the link rinethod.

The process that solid snow-ice yas formed and then repeatedly compacted by wheels can be considered as the process of cyclic load applied, a series of frozen-thaw and frozenadhesion will also formed according to the friction between wheels and snow-ice. Armann Norheim [14] considered that snow-ice was high pressure polymorph materials in the stress condition which is greater than $1 \times 10^{-5} \mathrm{E}$, the freezing grain brittle crack will be produced by adhesive crystals under the external force, which showed as the freezing adhesive strain yield performance.

\section{Materials and Methods}

\subsection{Instruments and Tools of Experiment}

DDL300 pres machine, signal acquisition system matching with DDL300 press machine, DH3818 strain gauge, DH3818 strain measurement system, computer, vernier caliper, serewdriver, wire stripper, electric iron, welding core, $150 \times 150 \mathrm{~mm}$ cement sample foil resistance strain gauge, multimeter, several of double color connection lines, a piece of $150 \times 150$ plate, a piece of $200 \times 200$ plate.

\subsection{Design of Experiment}

The factors of snow-ice characteristics contains snow thickness, density and firmness, which have of the freezing adhesive phenomenon, especially the greater influences to freezing adhesive yield characteristics thus set as three factors in experiment. The rotating orthogonal method of three factors and five levels was adopted in experiment, the coding scale of factors as shown in Table 1. 
Table 1. Coding Scale of Rotation Design Factors

\begin{tabular}{|c|c|c|c|c|}
\hline Level & Factor & Snow thickness $(\mathrm{cm})$ & Snow density $\left(\mathrm{g} / \mathrm{cm}^{3}\right)$ & Snow firmness $(\mathrm{Pa})$ \\
\hline & 1 & 2 & 481 & 1680 \\
\hline & 2 & 4 & 497 & 1826 \\
\hline & 3 & 7 & 521 & 2040 \\
\hline & 4 & 10 & 545 & 2254 \\
\hline & 5 & 12 & 561 & 2400 \\
\hline
\end{tabular}

\subsection{Design of Experiment}

The factors of snow-ice characteristics contains snow thickness, density and firmness, which have of the freezing adhesive phenomenon, especially the greater influences to freezing adhesive yield characteristics thus set as three factors in experiment. The rotating orthogonal method of three factors and five levels was adopted in experiment, the coding scale of factors as shown in Table 1.

\subsection{Process of Experiment}

The load of external force was applied to snow sample by using DDL300 press, the acquisition of the load of external force was completed by the signal acquisition system matching with press machine. The applied process of the external force load should be in full according with each other in the every group of experiment. The strain gages were pasted between concrete sample with snow-ice and the strain signal was transmitted to DH3818 strain gauge when the load of external force applied, the strain value measured by the strain gauge and the csignal transmitted to PC machine and the strain curve obtained by using the corresponding software.

The applied load of expernal force of single group snow sample was gradually increasing until the fold point suddenly appeared in the compression curve as shown in Figure 2, the acquisition of the strain was stopped when fracture crack appeared in snow layer as shown in figure ?. Freezing adhesive yield characteristics didn't embody regularity due to the serious stress concentration caused by the link method of crystals in snow and ice bas changed after snow layer fractured.

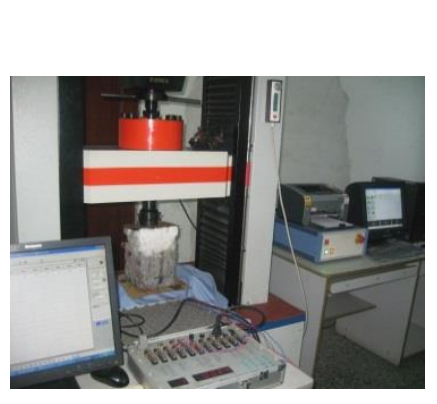

Figure 1. Practical Measurement Device

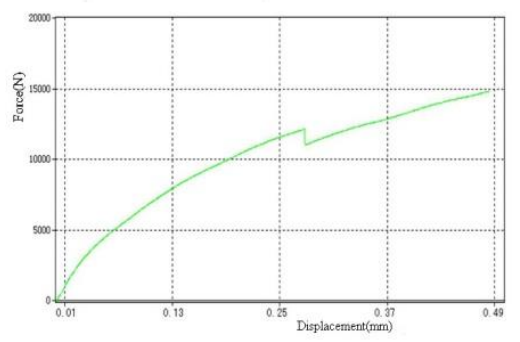

Figure 2. Compression Curve of Solid Snow-Ice

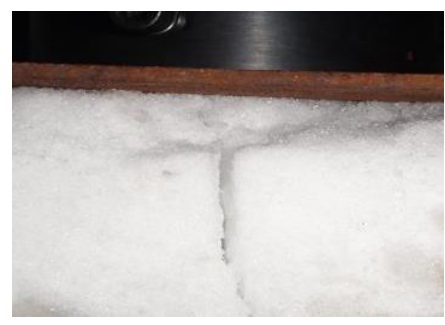

Figure 3. Snow-ice

Fracturing in Experiment 


\section{Results and Discussion}

\subsection{Analysis of Strain Curve}

The cycle strain curve of snow-ice under the cyclic load are as shown in Figure 4,the cycle strain condition of snow-ice that with the time passing under the cyclic load is described. The real process, that the snow-ice is repeatedly compacted is simulated in the process that the solid snow-ice is formed. The strain of solid snow-ice under the cyclic load could be expressed by three aspects: $\varepsilon=\varepsilon_{\mathrm{e}}+\varepsilon_{\mathrm{d}}+\varepsilon_{\mathrm{v}}$, which the total strain is $\varepsilon$, pure elastic strain is $\varepsilon_{\mathrm{e}}$, delayed elastic strain $\varepsilon_{\mathrm{d}}$, permanent strain is $\varepsilon_{\mathrm{v}}$. Thus the micromechanisms dealing with snow and ice include not only elasto-plastic deformations but also delayed elastic phenomena. The relation of these parameter function depend on the effect of freezing adhesion between road surface with snow-ice, such as bonding characteristics, contact surface characteristics and so on. The varrations such as temperature, damage of initial condition, crack opening, crack closure, the changes of compacting function should be considered in the process of freezing adhesive function.

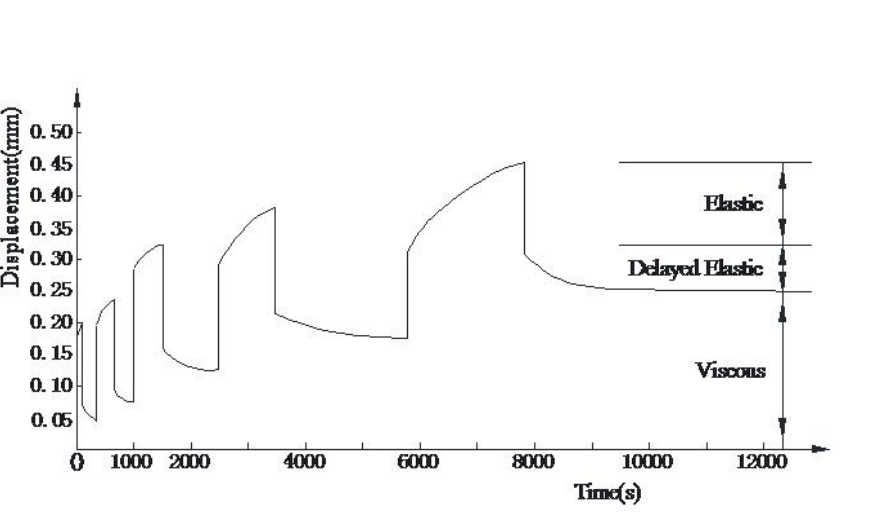

Figure 4. Cycle Strain Curve of Snow-ice under the Cyclic Load

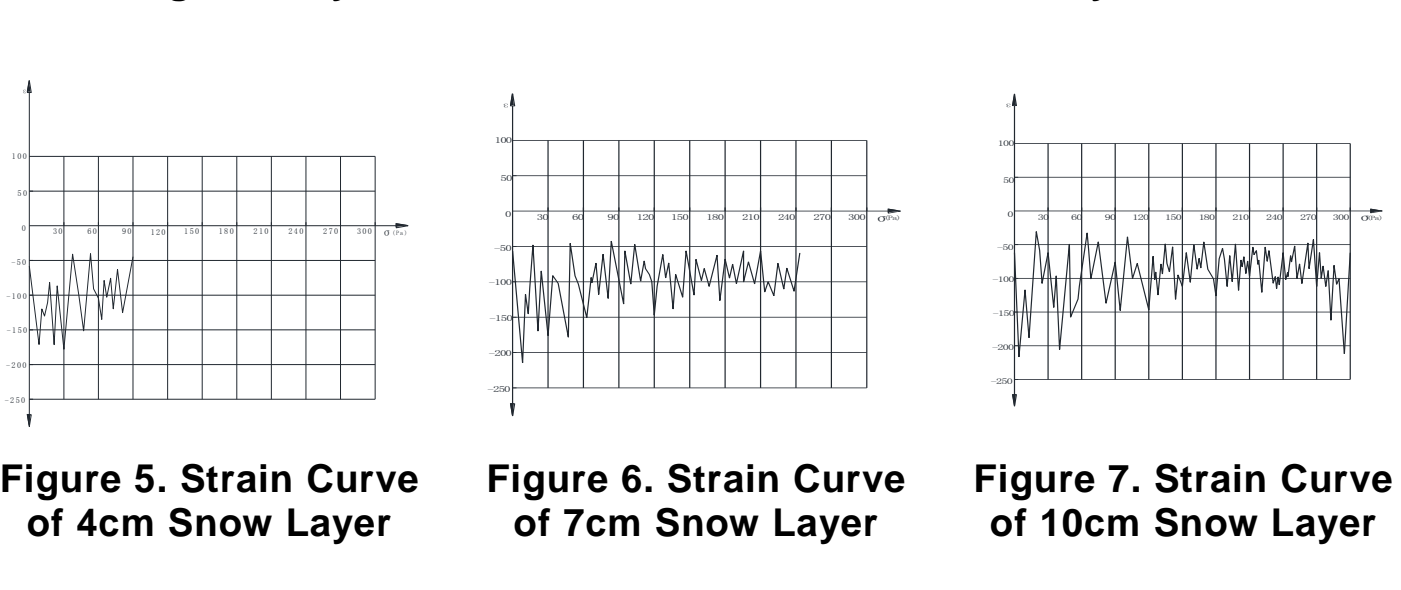

The strain curve of solid snow-ice freezing adhesive yield characteristics collected by the DH3818 strain gauge are shown in Figure 5, Figure 6 and Figure 7. The strain curve of $4 \mathrm{~cm}$ snow layer is shown in Figure 5, the strain curve of $7 \mathrm{~cm}$ snow layer is shown in Figure 6, the curve of strain $10 \mathrm{~cm}$ snow layer is shown in Figure 7 . The strain that collected by the strain gauge is the total strain $\varepsilon$. According to the strain curve, the trend of strain in the process that the applied load shows a fluctuated change, the strain value changes as a process of increase-decrease-increase. The reason is that some pores 
exist in snow layer at the very beginning and pure elastic strain is produced by these pores under the load, the strain is very obvious and the whole amplitude are larger at this period; the change of strain amplitude significantly reduced when the pure elastic strain is reaching to the delayed elastic strain, finally the change of strain amplitude slightly increases when the pure elastic strain reaches to the permanent strain and the strain increases suddenly until the snow-ice fracture suddenly occurred, this phenomenon leads to stress concentration because of the links between the crystal parts suddenly fractured and cohesion between the crystal damaged.

\subsection{Factors Analysis}

Using the average value of each group collected strain as an index in experiment, the design scheme and results are shown in Table 2.

$$
\varepsilon=0.87-0.05 x_{1}-(1.88 E-003) x_{2}-(1.37 E-004) x_{3}+(2.07 E-003) x_{1}^{2}+(1.9 E-004) x_{1} x_{2}+3
$$

Table 2. Design Scheme and Result of Test

\begin{tabular}{ccccc}
\hline Name & Thickness $(\mathrm{mm})$ & Density $\left(\mathrm{g}\left(\mathrm{cm}^{3}\right)\right.$ & Firminess(Pa) & Strain average \\
\hline 1 & 4 & 497 & 1826 & 0.154 \\
2 & 10 & 497 & 1826 & 0.205 \\
3 & 4 & 545 & 1826 & 0.095 \\
4 & 10 & 545 & 1826 & 0.226 \\
5 & 4 & 497 & 2254 & 0.127 \\
6 & 10 & 497 & 2254 & 0.115 \\
7 & 4 & 545 & 2254 & 0.089 \\
8 & 10 & 545 & 2254 & 0.107 \\
9 & 2 & 521 & 2040 & 0.149 \\
10 & 12 & 521 & 2040 & 0.262 \\
11 & 7 & 481 & 2040 & 0.182 \\
12 & 7 & 561 & 2040 & 0.127 \\
13 & 7 & 521 & 1680 & 0.155 \\
14 & 7 & 521 & 2400 & 0.12 \\
15 & 7 & 521 & 2040 & 0.139 \\
16 & 7 & 521 & 2040 & 0.145 \\
17 & 7 & 521 & 2040 & 0.133 \\
18 & 7 & 521 & 2040 & 0.143 \\
19 & 7 & 521 & 2040 & 0.124 \\
20 & 7 & 521 & 2040 & 0.132 \\
21 & 7 & 521 & 2040 & 0.147 \\
22 & 7 & 521 & 2040 & 0.143 \\
23 & 7 & 521 & 2040 & 0.122 \\
\hline
\end{tabular}

The three factors regression equation is established by using the Design-Expert Software. In formula (1), the strain value of snow is $\varepsilon$, the thickness of snow is $\mathrm{x}_{1}$, the density of snow is $x_{2}$, the firmness of snow is $x_{3}$. 


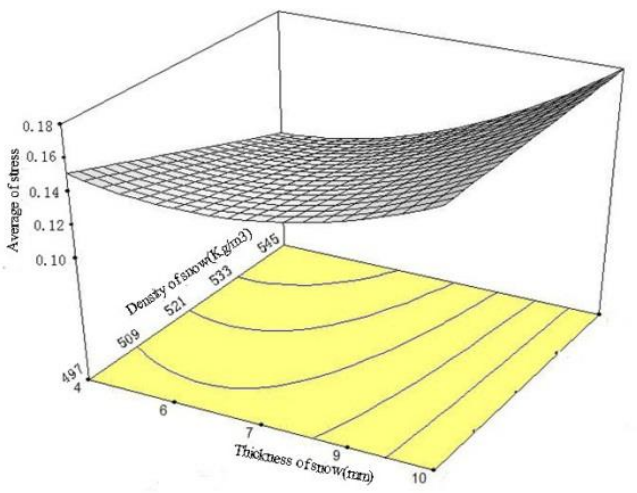

Figure 8. Response Surface Graph that the Thickness of Snow Layer and Density Effect on Strain

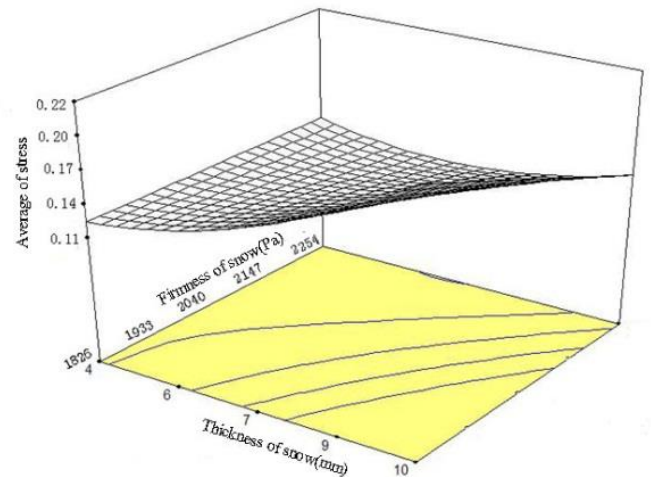

Figure 9. Response Surface Graph that the Thickness of Snovicayer and Firmness Effect on Strain

According to the figures 8 and 9 , there is the interaction between the thickness of snow layer, snow-ice density and snow-ice firmness. The strain value shows the trend of slowly rising after the first reduction with the increasing thickmess of snow layer when the snow-ice density is a constant. The strain value shows a trend of slowly reducing when the thickness of snow layer is a constant. The reason is that in the large density snow-ice, the cohesion between snow-ice crystal is large and the pore is relatively small. According to the figure 8 , the largen the thickness of snow layer, the larger the strain value when the firmness of snow-ice is a certain value; the firmness of snow-ice is larger, the strain value is smaller when the firmness of snow-ice is a constant. From all the above, the strain shows a trend of increasing after first reducing when the thickness of snow layer increase when both the density and the firmness of snow layer have been confirmed, it shows that the thickness of snow layer is the key factor affecting the clearing snow effect, but not the thickness is smaller, the effect is the better.

\begin{tabular}{|c|c|c|c|c|c|c|}
\hline $\begin{array}{l}\text { Source of } \\
\text { variance }\end{array}$ & & & $\begin{array}{c}\text { Mean } \\
\text { square } \\
\text { value }\end{array}$ & $\begin{array}{c}\mathrm{F} \\
\text { value }\end{array}$ & $\begin{array}{l}\text { Critical } \\
\text { value }\end{array}$ & Significance \\
\hline Model & 0.030 & 6 & $5.050 \mathrm{E}-003$ & 14.17 & $<0.0001$ & Significant \\
\hline A & 0,010 & 1 & 0.010 & 29.37 & $<0.0001$ & Significant \\
\hline B & $2.281 \mathrm{E}-003$ & 1 & $2.281 \mathrm{E}-003$ & 6.40 & 0.0223 & Significant \\
\hline $\mathrm{C}$ & $6.628 \mathrm{E}-003$ & 1 & $6.628 \mathrm{E}-003$ & 18.60 & 0.0005 & Significant \\
\hline & $5.539 \mathrm{E}-003$ & 1 & $5.539 \mathrm{E}-003$ & 15.54 & 0.0012 & Significant \\
\hline & $1.513 \mathrm{E}-003$ & 1 & $1.513 \mathrm{E}-003$ & 4.24 & 0.0560 & Significant \\
\hline & 3.872E-003 & 1 & $3.872 \mathrm{E}-003$ & 10.87 & 0.0046 & Significant \\
\hline $\mathrm{e}$ & $5.701 \mathrm{E}-003$ & 16 & $3.563 \mathrm{E}-004$ & & & \\
\hline Sum & 0.036 & 22 & & & & \\
\hline
\end{tabular}

The major and minor relationship of three factors are $\mathrm{A}>\mathrm{B}>\mathrm{C}$ which can be got from the analysis of variance as in Table 3 , that is thickness of snow layer>snow-ice density>snow-ice firmness. 


\subsection{Optimization Analysis}

The minimum snow-ice strain is required to obtain the lower ice cutting resistance failure. On the influence of each parameter and performance objectives evaluation contributes to the performance optimization of the ice and snow removing machine. According to the principle that the average strain of objective function is as small as possible, making the horizontal interval of each factor as constraint conditions, the optimized result is shown in figure 10 . When the parameter combination is: the snow density range is $500 \mathrm{~kg} / \mathrm{m} 3-518 \mathrm{~kg} / \mathrm{m} 3$, the thickness range of snow layer is $6.9 \mathrm{~mm}$ $7.5 \mathrm{~mm}$, the snow firmness range is $1826 \mathrm{~Pa}-2040 \mathrm{~Pa}$, the optimal average strain is 0.128 to 0.14 . Optimization analysis showed that when the cutting depth is $6.9 \mathrm{~mm}-7.5 \mathrm{~mm}$, density $500 \mathrm{~kg} / \mathrm{m} 3-518 \mathrm{~kg} / \mathrm{m} 3$, the snow firmness of $1826 \mathrm{~Pa}-2040 \mathrm{~Pa}$ can obtain the minimum strain range. It can provide valuable reference to the optimization parameters of snow removal machine if the experiment parameters are proved reasonable.

\subsection{Verification Test}

Within the scope of the optimization working condition, selecting the snow density $518 \mathrm{~kg} / \mathrm{m}^{3}$, the snow thickness $7 \mathrm{~mm}$, the snow fjumness $1826 \mathrm{~Pa}$, the minimum strain average forecasted by software is 0.134 , the average strain measured by test is 0.132 , the error is $1.5 \%$, verifying that the test results are in the optimization performance index range, so the optimized result is credible.

\section{Conclusions}

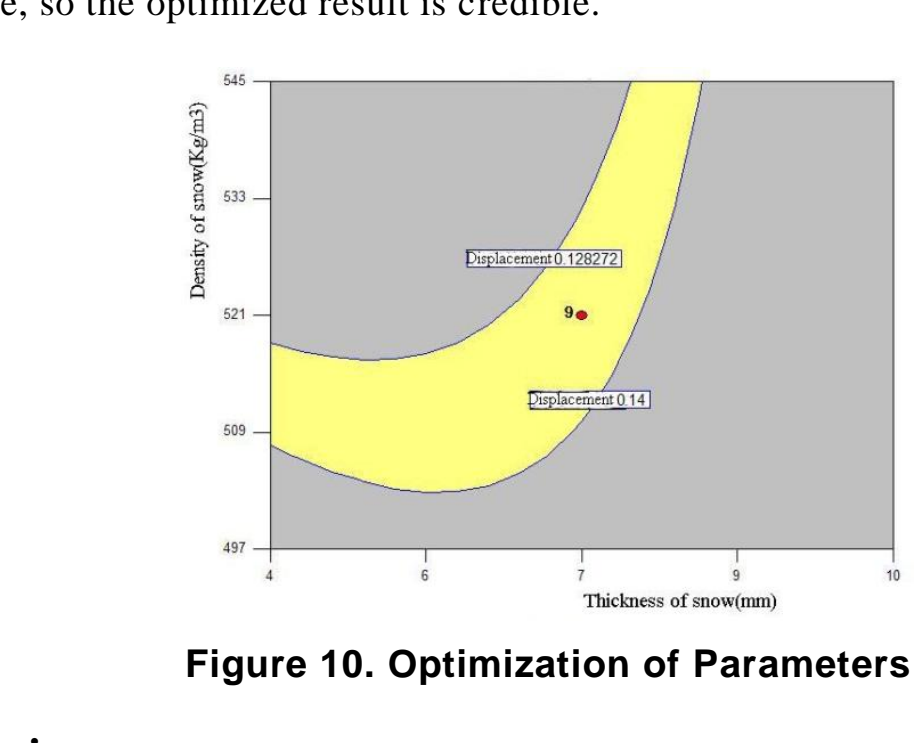

In this paper, deformation processes of snow and ice were described in term of three components - elastic deformation, delayed elastic deformation and permanent deformation. The strain collected by the experiment is the total strain $\varepsilon$, according to the strain curve, the trend of strain in the process that the applied load shows a fluctuated change, the strain value changes as a process of increase-decrease-increase. The snow-ice thickness has the most obvious influence to strain value according to the orthogonal rotation method of three factors and five levels. Three influence factors from major to minor is thickness of snow layer > snow-ice density > snow-ice firmness. There is interaction between snow layer thickness, snow-ice density and snow-ice firmness. As the most significant factors, identify the influence degree of thickness are suggested future research. 


\section{Acknowledgements}

It is a project supported by National Natural Science Foundation of China (51175226), by Jiamusi University Youth Fund ( Lq2012-34 ) ,by The Education Department of Heilongjiang Province (12521536).

\section{References}

[1] X. Yang and J. Li. "Summary on Mechanism of Freezing Adhesion and Anti-freezing Adhesion Techniques and Methods", Journal of Changchun Science and Engineering University, vol. 12, (2002).

[2] J. Wang, "Mechanism of Snow-ice Removing Using Vibration and Optimization of Vibration Roller", Changchun: Jilin University, vol. 5, (2011).

[3] J. Ding, "Experimental Research On Icing Surface Freezing Adhesive Characteristic", Shanghai; Shanghai Jiao Tong University, vol. 2, (2012).

[4] L. Ritz, "Ice formation on wings", Technical memorandums national advisory committee for aeronautics, vol. 888, (1939).

[5] I. A. Ryzhkin and V. F. Petrenko, "Physical mechanisms responsible for ice adhesion", Journal of Physical Chemistry.B, vol. 101, (1997).

[6] N. Sonwalkalkar, S. S. Sunder and S. K. Sharma, "Ice-solid adhesion analysis using low-temperature Raman microprobe shear apparatus", Spectroscopy, vol. 10, no. 47, (1993).

[7] F. Nico, "From Constitutive modelling of a snow cover to the design of flexible profective structures Part IMechanical modeling”, International Journal of Solids and Structures, vol. 41, (2004).

[8] J. B. Johnson, "Characterizing the microstructural and micromechanical properties of snow", Cold Regions Science and Technology, vol. 30, (1999).

[9] C. Pielmeier, "Stratigraphy and changes in hardness of snow measured by hand, ramsonde and snow micro penetrometer:a comparison with planar sections", Cold Regions Science and Technology, vol. 37, (2003).

[10] M. Christen, "RAMMS: Numerical simulation of dense snow avalanches in three-dimensional terrain", Cold Regions Science and Technology, vol. 63, (2010).

[11] Chiaia, "Triggering of dry snow slab ayalanches: stress versus fracture mechanical approach", Cold Regions Science and Technology, vol. 53, (2008).

[12] C. Fierz, "Assessment of the mierestructure-based snow-cover model SNOWPACK: thermal and mechanical properties", Cold Regions Science and Technology vol. 33, (2001).

[13] L. H. Shapiro, J. B. Johnson N1. Sturm and M. Blaisdell, "Snow mechanics-review of the state of knowledge and applications", USA Cold Regions Research and Engineering Laboratory, vol. 3, (1997).

[14] A. Norheim, N. K. Sinha, T. J. and Yager, "Effects of the structure and properties of ice and snow on the friction of aircraft tyres on movementarea surfaces", Tribology International, vol. 34, (2001).

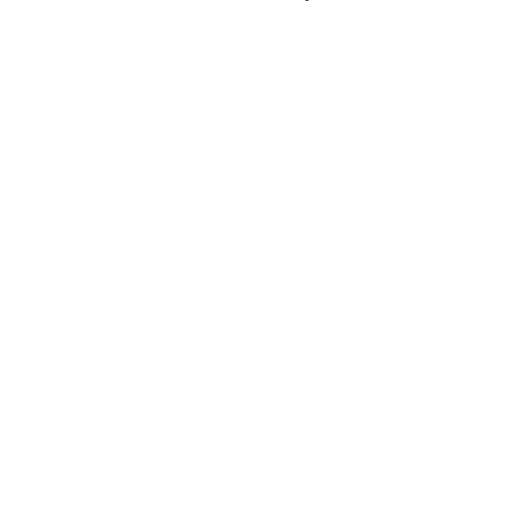

